\title{
PANORAMA DA INVESTIGAÇÃO DOS ESTUDOS : HISTÓRICOS E DIACRÔNICOS DAS LÍNGUAS E DOS TEXTOS
}

OVERVIEW OF THE RESEARCH OF HISTORICAL AND DIACHRONIC STUDIES OF LANGUAGES AND TEXTS

Maria Cristina de Assis (UFPB) ${ }^{1}$

\section{RESUMO}

Ao longo dos séculos, os estudos da linguagem foram abordados por teorias que se sucederam, trazendo, em geral, uma percepção diferente de língua e variação de paradigmas e de temas. No tocante às questões relacionadas à história e à mudança das línguas e dos textos, o objeto de investigação também não permaneceu o mesmo com o correr dos anos. Neste trabalho, objetiva-se discutir das principais orientações teóricas que nortearam os estudos históricos e diacrônicos das línguas, as principais temáticas, os questionamentos, as técnicas e os métodos utilizados, principalmente em relação ao português que se desenvolveu no Brasil nos últimos anos. Em seguida, enveredando pela discussão sobre a constituição de acervos documentais necessários à análise da história da língua, pretende-se abordar sucintamente as primitivas produções textuais em português numa época em que essa língua vulgar, que esteve à sombra do latim, ganha status de língua nacional. Interessa versar sobre temas peculiares a esses textos, como as primeiras questões gráficas, o florescimento de novos gêneros literários e a mudança gradativa no modo de encarar a língua e a relação entre esses textos e o estudo histórico da língua portuguesa nas universidades.

PALAVRAS-CHAVE: Linguística Histórica; história da língua portuguesa; produção textual em língua portuguesa.

1 Doutora em Letras Universidade Federal de Pernambuco e professora da UFPB. Email: cristinadeassis@hotmail.com 


\section{ABSTRACT}

Over the centuries, language, as an object of study, was approached by theories that, one after the other, presented different perceptions on language and variation of paradigms and themes. With regard to issues related to history and changing in languages and texts, the object of study has also differed through the years. This work aims to discuss the main theoretical orientations that have guided the historical and diachronic studies of language, their main themes, questions, and techniques and methods employed; mainly concerning the Portuguese developed in Brazil in recent years. Entering the discussion about the creation of documentary collections required for analyzing the history of language, we then intend to briefly address the primitive productions in Portuguese in a time when this vernacular, once under the shadow of Latin, reaches the status of national language. We understand to be important the reflection upon themes peculiar to these texts; such as the first spelling issues, the flourishing of new literary genres and the gradual change in the way of understanding the language and the relation between texts and the historical study of Portuguese in universities.

KEYWORDS: historical linguistics, history of the Portuguese language, text production in Portuguese.

\section{INTRODUÇÃO}

As questões relacionadas à história das línguas e dos textos são a temática deste trabalho. Para isso, focalizamos as principais orientações teóricas que nortearam os estudos históricos e diacrônicos das línguas, os questionamentos, técnicas e métodos utilizados. Abordamos também os textos como fonte de pesquisa para o estudo histórico das línguas, notadamente as primitivas produções textuais em português, as primeiras questões gráficas, o florescimento de novos gêneros literários e, finalmente, a relação entre o texto escrito e o a mudança gradativa no modo de encarar a língua, importante para o estudo histórico da língua portuguesa. 


\section{Sobre a perspectiva histórica nos estudos linguísticos}

Sabemos que a corrente teórica que estuda a língua numa perspectiva histórico-diacrônica, com vistas a entender a mudança das línguas é, em geral, a Linguística Histórica. Entretanto, mesmo antes do surgimento da Linguística moderna, a percepção histórica e textual já era presente nos estudos da linguagem na Ásia desde o século IV a.C., e na Europa na Antiguidade Clássica. Essas pesquisas ocupavam-se, principalmente, com textos literários escritos, encarados como obras de arte. Muitas vezes, os textos eram analisados numa perspectiva muito mais literária que linguística, observando a estrutura da linguagem em análises que tinham outros objetivos que não o ato linguístico em si mesmo: a preocupação em estabelecer o "certo" e o "errado" nas línguas, numa tendência normativa, buscando preservar as obras literárias e tornar inteligível a língua dessas obras.

Antes do século XVIII, os estudos baseados na comparação de línguas, de acordo com Robins (1983), eram trabalhos esporádicos, que representavam muitas vezes pesquisas e opiniões isoladas. Para a linguística antiga, até o século XIX, a linguagem era compreendida como uma realidade estável, atemporal, objetiva, fora do homem e, conforme Lyons (1981), não havia consciência de que a mudança linguística fosse universal, contínua e consideravelmente regular.

Em fins do século XVIII, as pesquisas começaram a se desenvolver em torno de questões históricas, com a descoberta e consolidação do método comparativo. Com o surgimento da Linguística Histórica, o objetivo dos estudos linguísticos passou a se reconstruir, através da comparação, a origem e a história das línguas. Criaram-se, a partir de então, áreas especializadas no estudo das diversas línguas indo-europeias, entre as quais se destaca o desenvolvimento da filologia românica e o estudo histórico-comparativo das línguas oriundas do latim, a partir da obra de Friedrich Diez.

Logo em seguida, com o movimento neogramático, surgiu uma orientação psicológica subjetivista na interpretação dos fenômenos de mudança, e o interesse passou dos estágios remotos das línguas para a investigação dos mecanismos de mudança linguística, através do estudo 
das línguas vivas. Nesse período, desenvolveram-se na Europa e na América, pesquisas fundamentadas, de um lado, nos primeiros comparatistas e, de outro, nos neogramáticos: gramáticas históricas, dicionários etimológicos e obras de filologia e história da língua, até hoje consultadas, principalmente no que se refere às origens e evolução da língua, nomeadamente nos aspectos morfológico e fonético.

No século XX, por influência de Saussure, as pesquisas linguísticas voltaram-se para os aspectos sincrônicos, em detrimento da diacronia. Mesmo assim, os estudos históricos continuaram a ser feitos na Europa e nos Estados Unidos. Na Linguística Histórica, predominaram duas linhas de pensamento: os que, a exemplo dos neogramáticos, percebiam as mudanças linguísticas como decorrentes de algo interno, inerentes à própria língua (estruturalismo e gerativismo) e os que consideravam as mudanças linguísticas como articuladas com o contexto social e com o falante (dialetolologia e sociolinguística) (FARACO, 2005).

Outra conhecida distinção foi defendida por Mattos e Silva (2008, p. 9): a Linguística Histórica strictu sensu, sentido estrito, e a lato sensu, sentido amplo. A primeira trabalha com dados datados e localizados, portanto, historicamente contextualizados: mudança das línguas, das maneiras como as línguas mudam e das causas e resultados de tais mudanças: os trabalhos sócio históricos de $S$. Romaine e a teoria da variação e mudança laboviana. A segunda analisa os fatores intralinguísticos ou (estruturais) e fatores extralinguísticos ou (sócio históricos): pesquisas estruturalistas, dialetológicas, sociolinguísticas, etnolinguísticas, teorias do texto, do discurso e da conversação, desde que estejam baseadas em corpora datados e localizados: estruturalismo diacrônico: Martinet (1955) e gerativismo diacrônico: D. Lightfoot (1979).

Mais recentemente, uma nova perspectiva histórico-diacrônica vem trazendo importante contribuição para a Linguística Histórica: as Tradições Discursivas (TD). Surgiu nos anos de 1960 - 1970, com origem na romanística alemã e apresenta uma visão diferenciada de fenômenos em mudança linguística, a partir da tríplice distinção de língua proposta por Coseriu (1979): o nível universal, o histórico e o textual. A distinção entre história da língua e história dos textos foi defendida por Brigitte Schlieben-Lange (1983, 1993), discípula de Eugênio Coseriu em Tübingen. 
Nesse contexto, entende-se que os fenômenos de variação e mudança das

: línguas podem ser influenciados pelas tradições dos textos.

O reconhecimento de que os estudos linguísticos não deveriam ser circunscritos à análise gramatical no nível da sentença, mas tomar por objeto o uso efetivo da língua através dos textos começou a partir da década de 70 do século passado, em diversas disciplinas das ciências humanas. Esse reconhecimento deu origem à linguística de texto. De acordo com Longhin (2014, p.16),

A motivação para o conceito de TD procedeu, de um lado, do reconhecimento de que o uso da linguagem, nas tantas esferas sociais, se faz sempre por meio de textos e que, portanto, o lugar de inovação linguística é o texto; e, de outro lado, dos debates, nas décadas de 1960 e 1970, em torno de questões de sociolinguística e de pragmática, aliadas a uma emergente linguística do texto.

Com as TD, a perspectiva textual retorna aos estudos históricos, mas os objetivos são diferentes das antigas análises filológicas. As Tradições Discursivas ocupam-se da história dos textos, seus usos, sua produção e processos de transmissão, entre outros aspectos, enquanto a Filologia tem como escopo principal a reconstituição e preservação dos textos. Vimos que uma das mais antigas atividades da Filologia e, no dizer de Auerbach (1972), “a mais nobre e a mais autêntica”, volta-se para a edição crítica de textos, buscando constituir textos autênticos e preservá-los dos estragos do tempo, das alterações e adições provocadas pelo descuido das pessoas, dos copistas. Além dessa, outra atividade filológica, a explicação de textos, ou comentários, tão antiga quanto a primeira e, muitas vezes, servia para promover o estudo gramatical e o da versificação. Para essa atividade, interessavam textos literários, obras dos autores clássicos perdidas no tempo e de que se tinha notícia muitas vezes através de cópias ou da referência de outros autores, e a língua falada do cotidiano, tanto da aristocracia quanto do povo, ficou negligenciada. 


\section{O texto escrito como fonte de pesquisa para o estudo histórico da língua}

Considerando que a descrição da história de uma língua se faz a partir dos textos - orais e escritos - produzidos nessa língua, a questão central passa a ser, então, a fonte para o estudo de épocas anteriores das línguas. Primeiramente, a fidelidade à língua falada no período estudado, já que a pesquisa baseia-se em textos escritos. Ivo Castro explica que, ao pesquisar a língua contemporânea, é possível ao linguista reconhecer se determinada forma pertence ou não à sua língua, se a estrutura é gramatical ou agramatical, o que não ocorre com textos de outras épocas: diante de uma passagem obscura, o linguista historiador da língua não pode simplesmente confiar na sua competência de falante e no seu discernimento:

O estudo dos estados passados de uma língua não pode contar com a experiência e a observação directa do linguista, mas apenas com os dois clássicos métodos conjecturais da reconstrução desses estados, baseada na comparação entre as variedades contemporâneas deles geneticamente decorrentes, e da exploração das fontes escritas produzidas na época que é objecto de atenção. (CASTRO, 1991, p.173)

Outros aspectos também são fundamentais, determinando os critérios que devem nortear a seleção do corpus: se os textos a serem reunidos devem ser formais ou informais, literários ou não, pessoais ou públicos. A preocupação com o rigor na seleção, transcrição e disponibilização das fontes é central em qualquer pesquisa, pois uma análise fundamentada num recorte mal construído poderá levar a conclusões distorcidas ou equivocadas. Não raramente o documento que chega aos dias atuais foi modificado pela mão dos escribas, condicionado por diversos fatores como o dialeto natal, o dialeto do local de produção do documento, o aprendizado da escrita, os modelos de documentos em que se inspira.

Rosa Virgínia Mattos e Silva apresenta a dificuldade de encontrar os dados para a pesquisa de acordo com o propósito do pesquisador como um problema central e geral em relação à questão das fontes: 
o conhecimento de qualquer estágio passado de qualquer língua - se ela é documentada por algum tipo de escrita ou de inscrição - é sempre fragmentado, porque fragmentário é o espólio de que dispõe o pesquisador. $\mathrm{O}$ investigador dessa fase da história da língua não constituirá seu corpus, de acordo com os objetivos de sua pesquisa, mas terá de condicionar a seleção de seus dados à documentação remanescente. A partir desse condicionamento inicial é que recortará os dados que julgue necessários e suficientes para responder a suas questões. (MATTOS E SILVA, 1991, p.28-9)

No caso da língua portuguesa, desde a formação do galego-português até o século XVI, quando foram publicadas as gramáticas, o percurso seguido pela língua foi documentado através de fontes escritas primárias ${ }^{2}$. Tradicionalmente, essas fontes existentes, após a formação do romance galego-português, são divididas em dois grandes grupos: a documentação literária, envolvendo a poesia (a lírica galego-portuguesa ou cancioneiro medieval português) e a prosa; e a não-literária (textos de natureza jurídica, administrativa, econômica e privada).

Cabe aqui uma observação sobre a utilização de textos literários como fontes de estudos linguísticos épocas anteriores da língua. Em geral, embora sejam ricos linguisticamente, por serem muitas vezes copiados, sofrem sucessivas modificações, interpretações e atualizações, dificultando a identificação do autor, data e local de produção. Além disso, em relação à fase inicial da produção escrita, praticamente não sobreviveram manuscritos literários possivelmente produzidos em Portugal em épocas anteriores ao século XIII, embora, como afirma Ana Maria Martins (2004, p.5):

hoje geralmente aceite que a arte poética dos trovadores se constituiu desde sempre em tradição escrita, circulando não em suporte de oralidade e memória mas em "folhas" soltas depois reunidas em cancioneiros individuais e em grandes compilações colectivas, parece não haver margem

2 Fontes primárias são as que ainda não se prestaram para o embasamento de uma pesquisa 
para duvidar de que havia produção literária escrita em português desde a segunda metade do século XII.”

Por outro lado, conforme ressalta Ivo Castro (2004), desde que as circunstâncias de sua produção sejam determinadas - o que um trabalho com disciplinas afins, como paleografia, a diplomática, a codicologia e a crítica textual, pode resolver -, nada impede que sejam tomados como documentos linguísticos.

Os textos não literários são geralmente apontados como preferidos pelos linguistas. As razões para essa preferência decorrem de serem textos com objetivos práticos e de, em geral, trazerem explícitos autor, local e data de produção. Dessa forma, permitem uma avaliação satisfatória do grau de correspondência e de identificação entre o texto e o dialeto falado no local e na época em que foram escritos, possibilitando a utilização para o conhecimento da língua oral da época (CASTRO, 2004). Por outro lado, mesmo mais próximos da oralidade que os textos literários, trazem maior grau de formalismos, às vezes difíceis de interpretar por quem não é paleógrafo.

Clarinda de Azevedo Maia, após analisar 186 documentos não literários escritos entre os séculos XIII e XIV, na Galícia e no noroeste português, concluiu:

Embora os documentos notariais de carácter particular não sejam um espelho fiel, uma reprodução da linguagem local, eles deixam transparecer certos factos da linguagem falada da época. Uma interpretação crítica desses documentos [...] permit [e] compreender a verdadeira natureza da língua escrita dos documentos não literários da Idade Média e manifest[a] ser impossível uma plena reconstrução dos estados pretéritos da língua. Tratando-se de uma linguagem escrita, e além disso, de carácter bastante artificial, a linguagem desses documentos medievais nunca reflecte fielmente a linguagem falada da época e da região a que se referem [...]. O seu valor como fontes de informação para o conhecimento da língua na Idade Média é [...] 
bastante variável: cada documento deixa transparecer, em diferentes proporções, certos traços da linguagem falada, de acordo com determinadas circunstâncias que podem influenciar, de modo mais ou menos acentuado, a maneira como cada notário escreve. Podem considerar-se factores verdadeiramente decisivos a educação e o grau de cultura do notário ou do escriba e a época em que o documento foi escrito. Relativamente a este último aspecto, pude comprovar que os documentos do século XIII e do início do século XIV, devido à influência da tradição latina notarial e, também em virtude de uma menor diferenciação das variedades regionais compreendidas na área estudada, deixam transparecer menos traços da linguagem falada do que os correspondentes ao período posterior. (MAIA, 1986, p. 950).

A produção não literária em língua portuguesa foi classificada por Lindley Cintra em quatro grupos: os diplomas reais, diplomas particulares, leis locais, leis gerais, classificados geográfica e cronologicamente. Do ponto de vista geográfico, foram divididos em duas grandes áreas. No Noroeste e no Oeste de Portugal, a produção documental primitiva, seja em latim seja em português, era mais abundante do que no Sul. Caracterizase por ser uma área densamente povoada, de atividade econômica intensa e presença de muitos mosteiros e igrejas que permitiam a conservação da documentação. Os documentos eram de carácter local e particular, dado o afastamento dos centros de poder. Já a região Centro-Sul era menos povoada, por sido tomada pelos mouros e retomada pela Reconquista, com poucos mosteiros, mas uma maior presença de ordens militares, além da corte (Coimbra-Lisboa). A documentação dessa região caracteriza-se por ser mais moderna do que a do norte, e a língua, homogeneizada pelo repovoamento, tornou-se modelo de elaboração linguística com a corte de Avis.

Em relação à classificação cronológica, a documentação primitiva em língua portuguesa pode ser dividida em duas fases, conforme Lindley Cintra (1963, p.45) e Ivo Castro (1991, p.183). A primeira fase vai desde as primeiras manifestações, na década de 1170 até a adoção formal como 
língua de registro dos atos oficiais do governo em 1255. A segunda fase surge a partir de 1255, na chancelaria do rei Afonso III de Portugal e se : estende até a institucionalização do português como língua escrita oficial no início do governo de D. Dinis, em 1279. Nesse período, o português já era usado, ao lado do latim nos diplomas oficiais (MARTINS, 1998 e 1999), mas, após a adoção do português como língua oficial, a produção de documentos escritos nessa língua passou a ocorrer com maior frequência.

Do período entre 1175 e 1255, há cerca de 30 textos escritos nos finais do reinado de Afonso III. São documentos que têm provocado discussões, primeiramente, porque muitos não estão datados, carecendo do estabelecimento de datações aproximadas; em segundo lugar, pela necessidade de se identificar os mais relevantes e, por último, por serem textos híbridos em latim e em português, precisando de uma avaliação quanto ao seu estatuto linguístico (CASTRO, 2004), (MARTINS, 2007). A seguir, vemos um quadro que resume a produção não literária em língua portuguesa, de acordo com a classificação de Lindley Cintra:

\section{Quadro 01}

\begin{tabular}{|c|c|c|}
\hline \multicolumn{3}{|c|}{ Primitiva produo no literria em lngua portuguesa - Sculo XIII } \\
\hline Grupo & & Documentos \\
\hline \multirow[t]{2}{*}{$\begin{array}{l}\text { Diplom as } \\
\text { reais }\end{array}$} & \multicolumn{2}{|c|}{$\begin{array}{l}1^{a} \text { fase - } 1096 \text { Cond. Portucalense - } 1095 \text { a } 1211 \text { - compilados por Rui } \\
\text { P. de Azevedo }\end{array}$} \\
\hline & \multicolumn{2}{|c|}{$\begin{array}{l}2^{a} \text { fase -D Afonso II }-1^{a} \text { diploma real em português, testamento } \\
(1214)\end{array}$} \\
\hline \multirow{3}{*}{$\begin{array}{l}\text { Diplomas } \\
\text { particulares }\end{array}$} & $\begin{array}{l}\text { Documentos em } \\
\text { latim }\end{array}$ & $\begin{array}{l}\text { A escritura de fundação da igreja de Lardosa, } \\
\text { de } 882 \text { ) a síncope do }-n \text { - intervocálico: moastica } \\
\text { (por monastica) }\end{array}$ \\
\hline & $\begin{array}{l}\text { Documentos em } \\
\text { português }\end{array}$ & $\begin{array}{l}\text { A Notícia de Torto, o Auto de Partilhas e o Testamento } \\
\text { de Elvira Sanches, (1192 e 1193) em português, } \\
\text { mas com protocolo e escatocolo latinos. Dois } \\
\text { documentos de Vairão, de } 1234 \text {, um de Ferreira } \\
\text { de Alves, de } 1236 \text {, três de Pedroso, de } 1243 \text { e } \\
\text { 1252. Notícia de Fiadores, de } 1175 \text { e de um } \\
\text { Pacto de Gomes Pais de Ramiro Pais, datável } \\
\text { de } 1173 \text {. }\end{array}$ \\
\hline & $\begin{array}{l}\text { Docum e n t o s } \\
\text { posteriores a } \\
1250\end{array}$ & $\begin{array}{l}\text { dois do Morgadouro, de } 1253 \text {, escritas em } \\
\text { português }\end{array}$ \\
\hline
\end{tabular}




\begin{tabular}{|c|c|c|}
\hline \multirow[t]{3}{*}{ Leis locais } & $\begin{array}{l}\text { Foros e os Foraisou } \\
\text { «costumes» } \\
\text { (cartas de } \\
\text { privilégios } \\
\text { locais) }\end{array}$ & $\begin{array}{l}\text { Foros de Garvão(1267) 11; Foros da Guarda } \\
\text { (copiado entre } 1273 \text { e 1282); Costumes de Terena } \\
\text { comunicados a Évora (1280); Costumes de Santarém } \\
\text { comunicados a Oriola(1294) -editados na série } \\
\text { PortugaliaeMonumentaHistorica, vol. II, Leges et } \\
\text { Consuetudines: }\end{array}$ \\
\hline & $\begin{array}{l}261 \text { forais, } \\
\text { datados de } \\
1095 \text { até } 1279 \\
\text { - redigidos } \\
\text { em latim e } \\
\text { com graus } \\
\text { diferentes de } \\
\text { romanceamento. }\end{array}$ & (Leges et Consuetudines, vol. II, dos PMH. \\
\hline & \multicolumn{2}{|c|}{ traduções portuguesas dos forais latinos - a partir do séc. XIV. } \\
\hline \multirow[t]{2}{*}{$\begin{array}{l}\text { Leis gerais } e \\
\text { Inquirições }\end{array}$} & $\begin{array}{l}\text { Leisgerais-distante } \\
\text { da produção } \\
\text { primitiva e de } \\
\text { pouco valor } \\
\text { ling uís tico, } \\
\text { tanto por causa } \\
\text { da sua história } \\
\text { filológica como } \\
\text { pela origem } \\
\text { centralizada. }\end{array}$ & $\begin{array}{l}\text { séc. XIV-Livro das Leis e Posturas ou Livro das Leis } \\
\text { Antigas, conservado na Torre do Tombo. } \\
\text { séc. XV - Ordenaçôes de D. Duarte } \\
\text { Ordenações Afonsinas (de Afonso V), nos PMH, } \\
\text { vol. II, Leges et Consuetudines. }\end{array}$ \\
\hline & $\begin{array}{l}\text { Inquiricões } \\
\text { i n q u é r i t o s } \\
\text { efetuados por } \\
\text { ordem real - norte } \\
\text { do país, no séc. } \\
\text { XIII, (toponímia, } \\
\text { a ntroponímia, } \\
\text { sintaxe } \\
\text { pragmática). }\end{array}$ & $\begin{array}{l}\text { Inquiriçôes Gerais de D. Afonso II, de } \mathbf{1 2 2 0} \text {, em cópia } \\
\text { posterior a } \mathbf{1 2 8 9} \\
\text { Inquirições Gerais de D. Afonso III, de } 1258\end{array}$ \\
\hline
\end{tabular}

Baseado em Cintra (1963, apud Castro, 2004)

Apontados como primeiros textos em língua portuguesa estão a Notícia de Fiadores de Paio Soares Romeu (1175), a anotação de despesas de Pedro Parada, e o Pacto entre Gomes Pais e Ramiro Pais, não datados, mas presumivelmente próximos de 1751, (MARTINS, 2007). Para Mattos e Silva, os "representantes incontestáveis conhecidos da primeira fase da primitiva documentação em português” são um documento real, o 
Testamento de Afonso II, escrito na Chancelaria desse rei em 1214, e um documento privado, a Notícia de Torto, datado, possivelmente, entre 1210 : e 1216.

Como se vê, a cronologia para a emergência do português, ou seja, a datação dos textos mais antigos em português não é consensual entre os pesquisadores, seja pelo hibridismo de alguns, escritos parte em português e parte em latim, seja por divergências em relação à data em que foram escritos. Além disso, é possível que novas pesquisas tragam à luz outros documentos até mais antigos. Nesse sentido, concordamos com Esperança Cardeira, quando afirma:

Mas mais importante que antecipar a data do "mais antigo documento em Português" é percebermos que a produção de documentos em Português, embora esporádica até à segunda metade do século XIII, é uma realidade que acompanha a fundação do reino. (CARDEIRA, 2004, p. 47).

Os textos antigos em português revelam a existência de duas tradições na escrita: uma pluriforme, com tendência conservadora, que segue o sistema ortográfico latino e outra inovadora, estabilizada, que prenuncia a constituição de normas gráficas. Ana Maria Martins (1999; 2004) classifica essas tradições como escrita portuguesa conservadora, como a Notícia de torto, e escrita portuguesa inovadora como o Testamento de Afonso II. Eles compõem um conjunto de textos de natureza jurídica, categorizados como fintos ou róis, notícias e testamentos (Martins 1997, p.7).

Além dessa produção textual em gêneros de caráter não literário, encontram-se os textos literários produzidos no período do português Arcaico: contados em mais de mil e quinhentos poemas trovadorescos - a poética galego-portuguesa - preservados em Cancioneiros. A poesia lírica floresce entre finais do século XIII a meados do século XIV. Escritas em galego-português, as cantigas foram conservadas em compilações, como os cancioneiros (coletâneas de poemas medievais). Nos cancioneiros, as poesias coletadas encontram-se em três categorias, além das cantigas de Santa Maria: Cantigas d'amigo - poemas de amor, por vezes com traços populares, em que fala a mulher; são inspiradas nas muwaššahas, poemas 
dos séculos XI e XII, escritos em hebraico ou em árabe; Cantigas d'amor

: - poemas mais eruditos, de frequente inspiração provençal, nos quais é o homem quem fala e, finalmente, Cantigas d'escarnho e de maldizer poemas satíricos, não raro extremamente grosseiros.

No começo do século XV, grandes mudanças ocorrem em Portugal. Com a nova monarquia, surgem inovações sociais e culturais. A língua portuguesa estende-se a todos os ramos do pensamento e o falar de Lisboa torna-se modelo linguístico. A literatura passa a envolver outras áreas: crônicas, traduções, nobiliários, novelas de cavalaria, tratados de teologia, historiografia. A escola literária galego-portuguesa extingue-se e, na corte, florescem a prosa literária e a poesia palaciana. Entre os séculos XV e XVI, o império português de ultramar foi construído, levando a língua a outros continentes, em novos gêneros textuais com as cartinhas (cartilhas) para aprender a ler e a escrever, os autos, os vocabulários, influenciando e sendo influenciado por outras línguas. Por outro lado, o surgimento da imprensa permitiu maior difusão e acessibilidade de livros e, consequentemente, aumento da produção literária. Seguiu-se um período de normatização e elaboração da língua portuguesa, centrada no eixo centro-meridional, fazendo com que as marcas linguísticas arcaicas sejam abandonadas e outras marcas, iniciadas em séculos anteriores, se estabeleçam.

A produção escrita amplia a reflexão sobre a língua portuguesa, ocasionando a publicação das primeiras gramáticas, a partir do século XVI. A língua já não é encarada apenas como meio de transmitir uma mensagem, mas como objeto de estudo em si. Além disso, havia ainda o interesse em divulgar, valorizar e louvar a língua enquanto instrumento de consolidação do império. O português passou a ser descrito, analisado, estudado em suas características. Outros estudos aparecem, como as edições paleográficas ou diplomáticas e edições críticas, glossários, dicionários etimológicos, histórias da língua, entre outros estudos, que funcionam como fontes primárias e secundárias para o estudo da língua. A produção textual do português clássico, que se estende de meados do século XVI ao século XVIII, compreende estudos linguísticos, gramáticas, dicionários, lexicografias, novela sentimental, epopeia, academias/teatro de cordéis, relatos de viagens e naufrágios, além dos textos de caráter administrativo, filosófico, notarial, comercial, particular etc. 
A partir do século XVIII, o português tornou-se instrumento de comunicação de mais de duzentos milhões de pessoas, com uma grande : diversidade de falares resultantes da transplantação da língua para outros países e do contato com outros povos e outras culturas. O interesse pelo ensino do português e pela alfabetização ampliou-se, intensificaram-se os estudos sobre ortografia, etimologia, norma culta, ciências.

Transplantado para outros países, o português afirmou-se em algumas regiões, tornando-se instrumento de comunicação entre povos, culturas e nações distantes. Em outras, originou línguas crioulas de base portuguesa ou, ainda, somou-se às línguas autóctones. Mesmo assim, segundo Cardeira (2006), o português Moderno, do século XVIII até o momento atual, apresenta diversidade, mas não tem apresentado mudanças radicais. Com as influências das diferentes línguas com que mantém contato, é possível que novas normas sejam constituídas, o que depende não somente de fatores linguísticos, mas também de fatores não linguísticos. É o que ocorre no Brasil, nos dias de hoje, em que se admite uma norma linguística autônoma, diferente da europeia, mas ainda integrante da língua portuguesa.

\section{CONSIDERAÇÕES FINAIS}

Abordamos neste texto a perspectiva histórico-diacrônica dos estudos linguísticos e, focalizando a constituição de acervos documentais necessários à análise da história da língua, destacamos a progressiva produção detextos escritos em português, a partir do período em que passa a ganhar status de língua nacional. Essa escrita surge timidamente, à sombra do latim, ganha projeção e, ao longo de sua história, realizase nos mais variados gêneros textuais, orais e escritos, literários ou não, formais e informais, à medida que a língua portuguesa assume múltiplas funções sociais, tornando-se instrumento de comunicação entre povos de culturas e geografias diversas, como língua da administração, da imprensa, da literatura, do ensino e das relações com outros povos. 


\section{REFERÊNCIAS}

: CARDEIRA, Esperança. O Essencial sobre a História do Português Brasileiro. Coleção: O Essencial. Coordenação: Maria Helena Mira. Lisboa: Editora Caminho, 2006

CASTRO, Ivo. Curso de História da língua portuguesa. Lisboa: Universidade Aberta. 1991.

- A primitiva produção escrita em português. Orígenes de laslenguas romances em el Reino de León. Siglos IX -XII, León, Centro de Estudios e Investigación San Isidoro, 2004, vol. II, p. 69-97. http://www.clul.ul.pt/ files/ivo_castro/2004_Primitiva_produo_escrita.pdf (2004).

CINTRA, L. F. Lindley, Lesancienstextesportugais non-littéraires. Classementetbibliographie, Revue de LinguistiqueRomane, XXVII, 1963, 40-77; 2.ำ ed. Lindley Cintra. Homenagem ao Homem, ao Mestre e ao Cidadão, Lisboa, Cosmos, 1999, 199-215.

FARACO, Carlos Alberto. Linguística histórica: São Paulo: Ática, 1991.

KABATEK, Johannes. Sobre a historicidade de textos. Disponível em: www.revistas.usp.br/linhadagua/article/view/37270.

MAIA, M. C. de A. História do galego-português. Estudo linguístico do galego e do noroeste de Portugal desde o século XIII ao século XIX (com referência à situação do galego moderno). Coimbra: INIC, 1986.

MARTINS, Ana Maria. O primeiro século do português escrito. $\mathrm{Na}$ NosaLyngoage Galega. A Emerxencia do Galego como Lingua Escrita na Idade Media, ed. Ana BoullónAgrelo. Santiago de Compostela: Consello da Cultura Galega \& Instituto da Lingua Galega. 161-184. 2007. Disponível em http://www.clul.ul.pt/files/ana_maria_martins/MartinsPrimeiroSeculo. pdf

- A emergência do português escrito na segunda metade do século XII.Estudos de filoloxía galega ofrecidosen memoria de Fernando R. Tato Plaza, ed. Rosario Álvarez \&AntónSantamarina. A Coruña: Fundación Pedro Barrié 
de laMaza. 491-526. [2004]. Disponível em:http://www.clul.ul.pt/files/ ana_maria_martins/MartinsEmergencia.pdf

MATEUS, Mira. A mudança da língua no tempo e no espaço. http://www. iltec.pt/pdf/wpapers/2005-mhmateus-mudanca_lingua.pdf

MATTOS E SILVA, R.V. Caminhos da Linguística Histórica - ouvir o inaudível. São Paulo: Parábola Editorial. 2008.

- A língua portuguesa em perspectiva histórica: do português europeu para o português brasileiro. Estudos Linguísticos (São Paulo), São Paulo, n. XXIX, p. 16-32, 2000.

TEYSSIER, Paul. História da Língua Portuguesa. Trad. de Celso Cunha. 6 ed. Portuguesa. Lisboa: Livraria Sá da Costa Editora, 1994. 